\title{
COVID-19 in children with cancers and post-haematopiotic stem cell transplantation (HSCT) in Oman
}

\author{
Laila Al Yazidi ${ }^{1}$, Yasser Wali ${ }^{2}$, and Abdulhakim Alrawas ${ }^{1}$ \\ ${ }^{1}$ Sultan Qaboos University Hospital \\ ${ }^{2}$ Sultan Qaboos University Hospital, College of Medicine and Health Sciences
}

August 6, 2020

\section{To the editor,}

Coronavirus Disease 2019 (COVID-19) has emerged as a major new public health threat, with high rates of morbidity and mortality among patients with chronic medical conditions. The Disease was classified as pandemic by March 2020 after its widespread over the world.(1)

Globally, up to $28^{\text {th }}$ July 2020, there has been more than 16 millions of confirmed cases of COVID-19, causing more than 650,000 deaths with the fatality rate of almost $4 \%$.(2)As of $28^{\text {th }}$ July 2020 , a total of 77,904 laboratory confirmed COVID-19 cases reported in Oman with mortality rate of $0.52 \%$. Up to this date, 6315 children $<14$ years of age were diagnosed with COVID-19 which account for $8.1 \%$ of total confirmed cases with no recorded deaths.(3) In Oman, children with mild COVID-19 are managed at home and those with moderate and severe disease are managed as inpatients. Ludvigssonet al in their systematic review found that COVID-19 in children tend to have a milder course and better prognosis compared to adults. (4)There is a limited literature describing SARS-CoV-2 infection in children with cancers and post haematopiotic stem cell transplantations . (5)

Despite extensive testing of any fever or URTI symptoms in these vulnerable children, there were only 3 children with cancersand post-haematopiotic stem cell transplantations (HSCT) tested positive and required admission for COVID-19 in Oman for the last 5 months; 2 with acute leukemia and one is post-HSCT for primary immune deficiency. Patients were tested for SARS-CoV-2 infection by sending nasopharyngeal specimens either for clinical suspicion of COVID-19 or as a screening following exposure to SARS-CoV-2. The first one has relapsed acute lymphoid leukemia (ALL) and was admitted for non-COVID-19 related issues. He has mild course of COVID-19 and chemotherapy was stopped with no additional management. Another child with ALL who has just completed his chemotherapy courses was admitted for pneumonia and started on oral azithromycin for 3 days and IV ceftriaxone for 1 week. His CBC remained normal with normal coagulation profile, D-dimers andCRP of $7 \mathrm{mg} / \mathrm{l}$. He was discharged in excellent good general condition. The $3^{\text {rd }}$ patient is post-HSCT for primary immunodeficiency tested positive for SARS-CoV-2 following surveillance done following exposure and was admitted for short period for non-COVID-19 related issues.

Although there is a theoretical concern that children with cancers are at risk of severe COVID-19 because they are immunocompromized, the limited available data does suggest that COVID-19 in this population is generally mild with self-limited course similar to the presentationof SARS-CoV-2 infection in healthy children. (5)Our series of children with cancers and post-HSCT showed similar results to what have been described in Italy, France and United States. Boulad et al. reported a low overall morbidity of COVID-19 in children with cancer with only 5\% (1/20) required hospitalization for management of COVID-19. (6)Rossoff et al described their experience from Chicago where they reported 6 children with cancers and post HSCT who 
got SARS-COV-2 infection. All of them had mild SARS-CoV-2-related symptoms and none were admitted for COVID-19 related issues. (5)Nazon et al described 6 children managed by their haematology/oncology unit at Strasbourg, France over 3 months period and all were either asymptomatic or have mild disease and none require admission for management of COVID-19.(7)Flash survey on children with cancer from 25 countries which follow up about 10,000 children at risk by March 2020, revealed that 9 out of $>200$ children tested for COVID-19 had the infection and 8/9 were either asymptomatic or have mild course.(8)

Severe COVID-19 has been described among five children $(5 / 33,15 \%)$ by a prospective nationalsurvey conducted by the French society of pediatriconcology among 30 French centers by Mid-April. These children required intensive care for respiratory support following mild initial course of COVID-19. At the time of writing the report, 4 of them were still managed in ICU and none have died.(9)

The Spanish Group of Transplantreported their experience of 8 children post HSCT with COVID-19; 5 required management as inpatients and 3 managed at home. Two children required intensive care admission for mechanical ventilation; one was still on extracorporeal membrane oxygenation (ECMO) and one died secondary to alveolar haemorrhage. Lymphopenia and low ratio CD4/CD8 was associated with severe COVID-19 in this small cohort. (10)

Our case series and the available experience reported from different countries showed that most of the children with cancer and post-HSCT have either asymptomatic or mild COVID-19 and these children have similar vulnerability and risk morbidity resulting from COVID-19 to healthy children.(11). Decisions on whether or not to postpone chemotherapy/HSCT need to made on a case-by-case basis and according to the risk of cancer progression which can results in a poor outcome. $(5,6)$

\section{References:}

1. WHO Director-General's opening remarks at the media briefing on COVID-19:11th March 2020. Published March 11, 2020. Available from: https://www.who.int/dg/speeches/detail/who-director-general-sopening-remarks-at-the-media-briefing-on-covid-19 - 20-march-2020 [Accessed 26th July 2020].

2. World Health Organization. Coronavirus (COVID-19). Available from: https://who.sprinklr.com/ [Accessed 27 July 2020].

3. World Health Organization. Coronavirus (COVID-19). Oman. Available from:https://who.sprinklr.com/region/emro/country/om [Accessed 27 July 2020].

4. Ludvigsson JF. Systematic review of COVID-19 in children shows milder cases and a better prognosis than adults. Acta Paediatr. 2020;109(6):1088-95.

5. Rossoff J, Patel AB, Muscat E, Kociolek LK, Muller WJ. Benign course of SARS-CoV-2 infection in a series of pediatric oncology patients. Pediatr Blood Cancer. 2020:e28504.

6. Boulad F, Kamboj M, Bouvier N, Mauguen A, Kung AL. COVID-19 in Children With Cancer in New York City. JAMA Oncol. 2020 May 13:e202028. doi: 10.1001/jamaoncol.2020.2028. Epub ahead of print. PMID: 32401276; PMCID: PMC7221844.

7. Nazon C, Velay A, Radosavljevic M, Fafi-Kremer S, Paillard C. Coronavirus disease 20193 months after hematopoietic stem cell transplant: A pediatric case report. Pediatr Blood Cancer. 2020:e28545.

8. Hrusak O, Kalina T, Wolf J, Balduzzi A, Provenzi M, Rizzari C, et al. Flash survey on severe acute respiratory syndrome coronavirus-2 infections in paediatric patients on anticancer treatment. Eur J Cancer. 2020;132:11-6.

9. Andre N, Rouger-Gaudichon J, Brethon B, Phulpin A, Thebault E, Pertuisel S, et al. COVID-19 in pediatric oncology from French pediatric oncology and hematology centers: High risk of severe forms? Pediatr Blood Cancer. 2020;67(7):e28392. 
10. Vicent MG, Martinez AP, Trabazo Del Castillo M, Molina B, Sisini L, Moron G, et al. COVID19 in pediatric hematopoietic stem cell transplantation: The experience of Spanish Group of Transplant (GETMON/GETH). Pediatr Blood Cancer. 2020:e28514.

11. Boulad F, Kamboj M, Bouvier N, Mauguen A, Kung AL. COVID-19 in children with cancer in New York City. JAMA oncology. 2020. 